INVESTIGACIÓN/RESEARCH

Recibido: 16/01/2014---Aceptado: 07/05/2014---Publicado: 15/06/2014

\title{
REMAKES A LA ESPAÑOLA. EL PROCESO DE ADAPTACIÓN DE SERIES EXTRANJERAS EN ESPAÑA
}

Belén Puebla Martínez': Universidad Complutense de Madrid (España).

bpuebla@ucm.es

Elena Carrillo Pascual: Universidad Rey Juan Carlos. Madrid, (España). e.carrillo.pascual@gmail.com

Paola Copado Sánchez-Rico: Universidad Nacional de Educación a Distancia. (España).paolacopado@gmail.com

\section{RESUMEN}

Las adaptaciones o remakes responden al éxito de determinados productos a nivel mundial, lo que incita a pensar en el creciente desarrollo de una cultura audiovisual cada vez más global. De esta forma, con el siguiente trabajo pretendemos analizar cuáles son las diferencias y las similitudes entre una serie de ficción extranjera y su adaptación en la televisión española, poniendo especial interés en averiguar cuáles son los elementos que sufren una mayor adaptación, así como de qué forma se modifican los guiones para conseguir un producto adecuado para el público español. Para ello, haremos un recorrido por las series de ficción adaptadas en España (en las cinco cadenas generalistas) en el periodo comprendido desde el año 2000 hasta 2013 a través de un análisis cualitativo en el que estudiaremos variables relacionadas con el contenido de los productos audiovisuales (características formales, personajes, cabecera, tramas, estética y diálogos) que nos permitan su comparación.

\footnotetext{
${ }^{1}$ Belén Puebla Martínez: Profesora de la Universidad Complutense de Madrid. Doctora en Ciencias de la Comunicación por la Universidad Rey Juan Carlos. Licenciada en Periodismo y en Comunicación Audiovisual por la URJC. Es directora del grupo de investigación Visual, investigando la comunicación en España. Es co-fundadora de la Revista Científica en Comunicación Aplicada Index. Comunicación de la URJC.
} 
Televisión - Series de televisión - Proceso productivo - Producción audiovisual Programa de entretenimiento - Programación televisiva

PALABRAS CLAVE: Televisión - Series de televisión - Proceso productivo Producción audiovisual - Programa de entretenimiento - Programación televisiva

\title{
SPANISH REMAKES. THE ADAPTATION PROCESS OF FOREIGN SERIES IN SPAIN
}

\begin{abstract}
The adaptations or remakes respond to the worldwide success of certain products, which encourages to think of the increasing development of a global media culture. Thus, in the following research, we claim to analyze what are the differences and similarities between a foreign TV series and its adaptation into Spanish television, with a particular interest in finding out which elements are suffering greater adaptation as well as in what way the scripts are been modified in order to offer an appropriate product to the Spanish public. To active this, we'll review the television series adapted in Spain (on the five generalist channels) from 2000 to 2013 through a qualitative analysis in which we'll study variables related to the content of the media products (formal characteristics, characters, headers, storyline, esthetic and dialogues) that allow us to compare them.
\end{abstract}

KEY WORDS: Television - Television series - Production Process - Media Production - Entertainment Program - Television Schedule

\section{INTRODUCCIÓN}

Actualmente, ya sea por la dificultad de crear proyectos originales o por el auge de ventas de formatos internacionales de éxito avalado en otros mercados, se observa una tendencia clara al aumento de producciones basadas en adaptaciones televisivas que tienen como base una serie extranjera. Este es el caso de Cámera Café (Telecinco, 2005-2009) o Doctor Mateo (Antena 3, 2009-2011).

El término "adaptar" tiene un significado específico cuando se refiere a las artes y el espectáculo. Adaptar es modificar una obra, de cualquier tipo, para que pueda difundirse entre un público distinto de aquel al que iba a ser destinado o, simplemente, darle una forma diferente de la original. De este modo, se sugiere la idea de que una adaptación artística está estrictamente vinculada a la necesidad de reinterpretar un producto según unas necesidades específicas de un colectivo, como puede ser asemejarlo al entendimiento propio de una cultura local.

Vemos por tanto, como el concepto de adaptación televisiva tiene en consideración el valor diferencial que supone ser un producto audiovisual con algunas modificaciones respecto a su versión original, de modo que el espectador de la serie adaptada pueda 
encontrar referencias culturales reconocibles; es decir, implica un vínculo elaborado desde la cultura en la que está contenido el público potencial de la adaptación.

El crítico e historiador cinematográfico José Luis Sánchez Noriega aporta la siguiente definición de adaptación:

El proceso por el que un relato, la narración de una historia, expresada en forma de texto literario, deviene, mediante sucesivas transformaciones en la estructura, en el contenido narrativo y en la puesta de imágenes, en otro relato muy similar expresado en forma de texto fílmico (Sánchez Noriega, 2000, p. 47).

Una definición precisa de adaptación, que nos sirve para diferenciar este producto de otros conceptos sería: la serie de ficción emitida, en este caso concreto en España, de cualquier género, la cual no es una idea original sino una copia reelaborada de una idea original, para su adecuación a la cultura local española. Esta adaptación puede modificar el comportamiento de algunos personajes, alargar o acortar tramas e introducir nuevos elementos narrativos para su correcto seguimiento y éxito. Además, la adaptación estará basada en los guiones originales, lo que repercute en una similitud entre los dos productos.

"La década de los 90 supone el arranque definitivo de la industria de la ficción televisiva nacional con la proliferación de las empresas de producción independiente" (Diego, 2010, p. 51). Más tarde, con la proliferación de cadenas privadas, el asentamiento de la TDT y el desarrollo de Internet, llegó el momento de invertir más dinero en las producciones de series televisivas con el fin de crear productos de calidad capaces de fidelizar a las audiencias. Por ello, fue necesario adoptar una política de compra de formatos existentes y de éxito contrastado en los mercados internacionales. La mayoría de adaptaciones de series extranjeras en el mercado televisivo español son ideas procedentes de Estados Unidos, Latinoamérica y Europa.

Esos formatos se compran en los grandes mercados televisivos donde acuden las cadenas y las productoras para encontrar ideas de series exitosas internacionales de posible realización en su propio país. Por ello, cada vez es más común la compra de un formato televisivo extranjero para su posterior adaptación en un determinado país. Este proceso de compra cuenta tanto con ventajas como con inconvenientes: 
Televisión - Series de televisión - Proceso productivo - Producción audiovisual Programa de entretenimiento - Programación televisiva

Tabla 1. Ventajas e inconvenientes de la compra de formatos televisivos

\begin{tabular}{|l|l|}
\hline Ventajas & Inconvenientes \\
\hline $\begin{array}{l}\text { Ahorro en la investigación de productos de } \\
\text { éxito nacional }\end{array}$ & $\begin{array}{l}\text { El proceso creativo se reduce notoriamente, } \\
\text { debido a que las adaptaciones deben ser fieles }\end{array}$ \\
\hline $\begin{array}{l}\text { Disminución de riesgo económico de la } \\
\text { industria audiovisual }\end{array}$ & $\begin{array}{l}\text { Disminución en la inversión de capital } \\
\text { económico y humano a la hora de desarrollar } \\
\text { ideas originales }\end{array}$ \\
\hline
\end{tabular}

Fuente: Guerrero (2010, p. 241).

Teniendo en cuenta estas ventajas e inconvenientes, se hace preciso conocer de forma más profunda cuáles son las características de estas producciones en nuestro país, y cuál es la forma en la que adaptamos estos productos a la cultura local para que se conviertan en series de éxito.

\section{METODOLOGÍA}

\subsection{Objetivo de estudio}

Con el siguiente trabajo pretendemos comparar los elementos y características de las series de ficción adaptadas con sus originales, con el principal objetivo de conocer cuáles de estos elementos son los que sufren una mayor transformación en el proceso de adaptación.

De esta forma, la investigación tendrá como propósito responder a los siguientes objetivos específicos:

1. Establecer un patrón o lógica que siguen los productos adaptados, remakes, del periodo de investigación 2000-2013.

2. Valorar de manera generalizada, a través de un estudio individual de cada serie, cuáles son los elementos de las ficciones originales internacionales que sufren una mayor "españolización" a la hora de ser adaptadas para el público español.

3. Reconocer las características propias de las series españolas y la necesidad de adaptar los formatos a la idiosincrasia de las parrillas nacionales.

\subsection{Metodología de análisis}

Para realizar este estudio, se ha realizado un análisis cualitativo de las series de ficción adaptadas en España, comprendidas en el periodo de 2000 a 2013. La decisión de centrar el estudio en este intervalo se debe a que la pasada década tuvo lugar el apagón analógico para dar paso al nuevo sistema de Televisión Digital Terrestre (TDT), que permitió un mejor aprovechamiento del espectro de difusión, ahorrando 
costes a los radiodifusores y con ello incentivando el desarrollo de canales privados de emisión abierta ${ }^{2}$.

Asimismo, la muestra de este estudio se redujo a las cinco cadenas de televisión generalistas en España, puesto que en el periodo de tiempo acotado para la investigación fueron las únicas que mantuvieron una producción periódica de este formato y generaron productos a nivel nacional, algo que no se dio en las cadenas autonómicas. Además, debido a la naturaleza del estudio, las series de ficción analizadas se redujeron al número de títulos de producción nacional que fueron adaptaciones de productos audiovisuales televisivos internacionales.

Debemos señalar, asimismo, que de los 14 proyectos se han analizado, en total, 11 series; las pertenecientes a las tres cadenas de televisión con las cuotas de audiencia más altas de entre los canales televisivos generalistas de España: Telecinco con un 13,9\% de share, Antena3 con un 12,5\% y en tercer puesto La 1 de TVE con un 12,2\% de share en el año 2012, según los datos publicados por Kantar Media.

Además de los 11 remakes, se han analizado también las 11 series de ficción extranjeras que los inspiraron, en total, 22 producciones. Para ello, por un lado se han expuesto los elementos ${ }^{3}$ que sirvan para identificar tanto a la adaptación española como a su original, es decir: título de la serie, canal de emisión, periodo de emisión y género de la serie. Por otro lado, se han analizado variables relacionadas con el contenido a través de la visualización del capítulo piloto tanto de la adaptación española como de su original de producción extranjera, es decir: características formales, personajes, cabecera, tramas, estética y diálogos.

\section{ANÁLISIS Y DISCUSIÓN}

La intención de un análisis individualizado respondió a la necesidad de ahondar en cada una de las producciones y compararlas, en cuanto a nivel de contenido, con su original, para percibir de esta forma las modificaciones existentes y poder determinar así cuáles eran los factores que hacían que una misma idea, llevada a cabo en dos países diferentes, terminase impregnada de matices locales o de limitaciones y necesidades a nivel de producción, que provocasen que se conviertan en dos productos totalmente distintos acaparando, en algunos casos, críticas y datos de audiencia muy distintos.

2 El día 8 de abril de 2009 el Consejo de Ministros, a través del Ministerio de Industria, Turismo y Comercio, cuyo ministro era Miguel Sebastián Gascón, anunció la apertura del plazo para que los operadores privados nacionales pudieran solicitar la modificación de sus concesiones de televisión, para ofrecer contenidos de pago a través del servicio digital terrestre.

${ }^{3}$ Se puede consultar el análisis cuantitativo de esta investigación en Puebla, B. Copado, P. y Carrillo, E. (2012). Una aproximación a la adaptación de las series extranjeras en España. Actas del V Congreso Internacional Latina de Comunicación Social. Tenerife: Sociedad Latina de Comunicación Social. Disponible en: http://www.revistalatinacs.org/13SLCS/2013_actas.html ISBN. 978-84-15698. 
Televisión - Series de televisión - Proceso productivo - Producción audiovisual Programa de entretenimiento - Programación televisiva

\subsection{Series cuyo original se haya emitido en España}

\subsubsection{Las Chicas de Oro (TVE, 2010)}

\begin{tabular}{|l|l|}
\hline Título: Las chicas de Oro & Título Original: The Golden Girls \\
\hline Cadena: La 1 (TVE) & Cadena: NBC (EE.UU.) \\
\hline Periodo: 2010 & Periodo: 1985-2001 \\
\hline Género: comedia & \\
\hline
\end{tabular}

El remake de Las Chicas de Oro lanzado por TVE en 2010 no fue la primera adaptación española de la exitosa serie americana The Golden Girls. Ya en el año 1995 se había producido la serie Juntas pero no revueltas. La versión aquí analizada corresponde a la producida por Alba Adriática en 2010.

Características formales. El proyecto del año 2010, producido por José Luis Moreno, reconstruye casi idénticamente, la idea original. No obstante, los capítulos de la adaptación eran de una mayor duración, en la línea de la ficción española. Así, mientras los episodios estadounidenses tenían una duración de 22 minutos, en la versión española alcanzaban los 50. Para conseguir este metraje, los guiones de cada episodio original se combinaban de dos en dos, dando lugar a un sólo capítulo en la serie adaptada.

Personajes. En esta versión, el reparto estaba compuesto por actrices de prestigio del panorama televisivo español. En la serie original aparecía Bea Arthur en el papel de Dorothy, Betty White como Rose, Rue McClanahan como Blanche y Estelle Getty como Sophia. En la versión española, Concha Velasco era Doroti; Carmen Maura, Rosa; Lola Herrera, Blanca, y Alicia Hermida, Sofía. Como se puede apreciar, los nombres de las cuatro protagonistas fueron traducidos literalmente.

Cabecera. La presentación de la versión española era instrumental, por lo que se descartó la canción de la cabecera original, el tema de Cynthia Fee Thank you for being a friend.

Episodio piloto. Como en la producción española cada capítulo de la serie estaba compuesto por dos de la americana, se analizaron únicamente el primero de ellos, titulado El robo. El primer dato destacable era que este capítulo se correspondía con el octavo episodio de la primera temporada americana. En ambos casos, el guión gira en torno a dos tramas. Por un lado, un ladrón ha entrado en la casa de las cuatro mujeres mientras que ellas se encontraban fuera; por otro, Rosa, al descubrir el robo, sufre una fuerte conmoción psicológica que le hace desarrollar un comportamiento paranoico que pone en peligro a sus compañeras.

Un concepto relevante a la hora de analizar la adaptación respecto a la versión original era la similitud del teaser ${ }^{4}$. En este caso existía un gran paralelismo: la

\footnotetext{
${ }^{4}$ Referido a la primera escena de la serie de ficción anterior a la cabecera.
} 
primera escena se situaba en la entrada de la casa de las cuatro mujeres, antes de encontrarse con la casa desbaratada por los ladrones. Esta escena era compartida por ambas versiones, siendo la española algo más larga. No era la única escena de la adaptación similar a la versión original. Realmente, el remake contaba con el mismo número de escenas que la producción americana y suceden, en ambas, lo mismo.

Estética. La ambientación, el vestuario y el atrezzo, en general, eran muy similares, encontrándose la mayor diferencia en la ropa y en los peinados que fueron modificados para adecuarlos a la moda actual. El número de decorados eran compartidos: el salón, donde se producía la mayor parte de la serie, una terraza, donde se solían cerrar los capítulos, y la entrada a la casa. Lo cierto es que esta similitud entre las dos producciones hacía que el espectador se encontrase ante una serie de ficción actual pero con continuas reminiscencias de los años ochenta, pudiendo llegar a despistar al espectador sobre si la adaptación estaba ambientada en el 2010 o en la década de su original.

Diálogos. Las modificaciones del guión en este aspecto también eran mínimas. Muchas frases eran reproducidas literalmente en gran parte de las escenas del capítulo, introduciendo, como única novedad, referencias contemporáneas actualizadas en algunos chistes, como "ella no va a ir pegando tiros como si fuera Lara Croft" o "¿tú crees que si me hubieran traído a Richard Gere me hubiera puesto así por el jarrón?".

\subsubsection{Yo soy Bea (Telecinco, 2006-2009)}

\begin{tabular}{|l|l|}
\hline Título: Yo soy Bea & Título Original: Yo soy Betty, la fea \\
\hline Cadena: Telecinco & Cadena: RCN (Colombia) \\
\hline Periodo: 2006-2009 & Periodo: 1999-2001 \\
\hline Género: dramedia & \\
\hline
\end{tabular}

Características formales. Su gran número de episodios (773), su emisión diaria, la dilatación de las tramas a lo largo de varios capítulos, el amor como base, y la duración de cada emisión (50-60 minutos), hicieron que Yo soy Bea fuera una telenovela al uso.

Personajes. En la versión original, la mayoría de los actores eran poco conocidos hasta el éxito de la telenovela. Sin embargo, en España, varios de los intérpretes de la versión ya eran actores reconocidos en el panorama televisivo nacional. Era el caso de Mónica Estarreado, que había participado en series como Al Salir de Clase (Telecinco, 1997-2002); o de Ruth Núñez, que interpreta a Bea, y que anteriormente había hecho papeles como el de Tania en Compañeros (Antena3, 1998-2002).

Cabecera. La cabecera de la versión española se inspiraba en la de la serie original, compuesta por escenas del día a día de Betty en la oficina, combinadas con la música del tema Se dice de mí, de Yolanda Ramos, en Colombia; y Te falta veneno, de Edurne, en España. En ambos casos los temas alcanzaron una gran popularidad. 
Televisión - Series de televisión - Proceso productivo - Producción audiovisual Programa de entretenimiento - Programación televisiva

Episodio piloto. Había modificaciones bastante significativas en el guión, dando a Yo soy Bea una personalidad propia, más cercana a la audiencia española. Se introdujeron más tramas en la versión española que en la original; por ejemplo, al comienzo de la adaptación, el personaje de Álvaro, antes de comenzar su relación con su actual novia, fue amante de la hermana de ésta, que había sido presuntamente asesinada. Estos acontecimientos abrieron la puerta a una trama de investigación, con diversos problemas para el protagonista desde el primer capítulo; esta trama era inexistente en la versión original.

Asimismo, la revista donde trabajan los personajes tenía distinto nombre, siendo Ecomoda en Colombia y Bulevar 21 en España. Además, en la versión española se sentaron las bases necesarias, desde el primer capítulo, para que el espectador asimilase la relación amorosa que se desarrollaría entre Bea y Álvaro, presentada como la trama principal para la audiencia española. La clave se encontraba en la adición de una escena inexistente en la versión original, en la que, por un descuido, Álvaro casi besa a Bea en los labios. En la serie colombiana, no es hasta el segundo episodio cuando Betty comienza a sentirse atraída por su nuevo jefe.

La primera escena del piloto no era igual en las dos versiones. Yo soy Betty, la fea comenzaba con un plano subjetivo de Betty andando hacia la entrada del edificio de Ecomoda, donde tiene la entrevista de trabajo, retrasando así el momento de que el público conozca el aspecto del personaje de Betty. En la versión española existía esta misma escena, pero la antecedía otra en la que Bea, a través de su voz en off, relataba la experiencia de dicha entrevista mientras la escribía en la Red. En este caso, un plano desde la posición de la cámara web del ordenador era la que presenta al espectador a Bea.

Estética. El número de decorados era mayor en la versión española, existiendo cinco escenarios fijos, además de varios polivalentes y más planos exteriores. En la versión original se apreciaban cuatro escenarios fijos, más dos planos rodados en exteriores.

Aunque la estructura de los decorados era similar (la redacción de la revista de moda, la casa de Bea), existía una diferencia sustancial en cuanto al atrezzo, ya que el mobiliario y el vestuario eran de factura mucho más moderna en la versión española. No podemos obviar el dato de que fue una adaptación llevada a cabo seis años después de su original. Este salto temporal también se manifiesta en la referencia, en Yo soy Bea, a las nuevas tecnologías, como las redes sociales en Internet, un medio por el que Bea se comunicaba con la comunidad feonauta, a quienes iba relatando el transcurso de su historia. Esta introducción de la tecnología en la telenovela fue algo nuevo que se incluye en el remake, siendo inexistente en la versión original. 


\subsubsection{Cheers (2011-2012, Telecinco)}

\begin{tabular}{|l|l|}
\hline Título: Cheers & Título Original: Cheers \\
\hline Cadena: Telecinco & Cadena: NBC (EE.UU) \\
\hline Periodo: 2011-2012 & Periodo: 1982-1993 \\
\hline Género: comedia & \\
\hline
\end{tabular}

Características formales. La aspiración principal de la serie de Telecinco era la integración de los recursos de una sitcom al más puro estilo americano: episodios de no más de 30 minutos donde se desarrollan dos o tres tramas, creación de situaciones cómicas reforzadas con risas enlatadas y gags, recurrencia de los mismos espacios (el bar) y un número cerrado de actores (cinco o seis).

El primer capítulo de la serie adaptada fue emitido el 11 de septiembre de 2011, 19 años después de que la NBC estrenara uno de los productos televisivos más exitosos de todos los tiempos. La versión española no consiguió finalizar su primera temporada, pese a que se emitió en dos periodos para intentar mejorar su audiencia.

Personajes La versión original americana consiguió el respaldo de crítica y público pese a disponer de una plantilla de actores no excesivamente conocidos. Más bien, algunos de ellos ganaron fama y prestigio gracias a sus papeles en Cheers. Por el contrario, la adaptación española contaba en su reparto con varios intérpretes de prestigio y larga trayectoria en la televisión y el cine nacional, si bien su trabajo en este proyecto, sin excepción, tuvo reminiscencias de personajes reconocibles que habían creado anteriormente. Tal es el caso de Antonio Resines, en un registro muy similar al de Diego de Los Serrano (Telecinco, 2003-2008).

Cabecera. Uno de los elementos que guardó más similitud entre original y adaptación de Cheers fue la cabecera, que, a pesar de diferir en muchos aspectos, puede considerarse una versión modernizada de la presentación americana. En ambos casos estaba basada en ilustraciones que representaban escenas antiguas del bar. La música, que en Estados Unidos estuvo a cargo de Gary Portnoy, cuyo tema Where everybody knows your name cosechó un importante éxito, en España se encomendó al cantante pop Dani Martín, que realizó una versión del tema español.

Episodio piloto. El número de tramas difería de una forma notable. En el piloto americano, titulado "Dame el anillo alguna vez", se relataba cómo la joven Diane Chambers era abandonada por su prometido en Cheers, el bar regentado por Sam Malone, un ex alcohólico y jugador de béisbol que no tardaría en sentirse atraído por la mujer y le ofrecería trabajo en el local. Era en esta localización donde se presentarían de forma escalonada el resto de personajes.

En España, el piloto "Corbatas y pigmeos" comenzaba con un striptease en honor a Félix, el personaje encarnado por Antonio Resines. La celebración terminaría en la ruptura del compromiso, cuando la prometida del psiquiatra, interpretada por un cameo de Ana Belén, irrumpía en el bar y descubría la escena. Por otro lado, Nico 
Televisión - Series de televisión - Proceso productivo - Producción audiovisual Programa de entretenimiento - Programación televisiva

(Alberto San Juan) se quedaba prendado de Rebeca (Alexandra Jiménez), hija de un antiguo amigo, Faustino (José Coronado). Éste era buscado por la policía por una trama de fraude y evasión de impuestos en África, lo que le llevó a abandonar a su hija en el local. Entonces, Rebeca se vio forzada a aceptar un puesto de camarera en Cheers.

Como es habitual en las series de televisión españolas, desde el primer capítulo se perfila una trama amorosa. En este caso resultaba mucho más evidente para los espectadores la atracción entre Rebeca y Nico desde el arranque de la serie que en el caso de Diane y Sam.

Estética. En la versión original, sólo existía una localización en el capítulo piloto: el interior del bar. El número de decorados era mayor en la versión española, existiendo localizaciones exteriores para representar al personaje de José Coronado en África. En cuanto al atrezzo y a los decorados, salvando la distancia estilística que marcan los 19 años entre las dos producciones, sí existía una similitud entre los elementos característicos de los dos bares, de inspiración irlandesa.

Diálogos. El guión no guardaba ninguna similitud en este sentido; tan sólo se respetaron la esencia de los personajes principales y algunos de sus rasgos, adaptando otras de sus características para que respondieran a los arquetipos humorísticos de la ficción española.

\subsubsection{Gavilanes (2010-2011, Antena 3)}

\begin{tabular}{|l|l|}
\hline Título: Gavilanes & Título Original: Pasión de Gavilanes \\
\hline Cadena: Antena3 & Cadena: Caracol TV (Colombia) \\
\hline Periodo: 2010-2011 & Periodo: 2003-2004 \\
\hline Género: drama & \\
\hline
\end{tabular}

Características formales. Gavilanes es una serie de ficción, en contraposición al carácter de telenovela que define a Pasión de Gavilanes, por lo que el ritmo de la adaptación fue más rápido que en la versión original. Mientras que de la serie original se realizaron casi 200 episodios de 50 minutos en una sola temporada, la adaptación se dividió en dos temporadas con un total de 26 capítulos de 70 minutos de duración.

Reparto y personajes. Los actores de Pasión de Gavilanes, como Mario Cimarro, Michel Brown, Danna García o Juan Alfonso Baptista, ya contaban con una larga trayectoria en telenovelas latinoamericanas. El elenco español escogido para el remake estaba compuesto también por actores conocidos, como son Rodolfo Sancho que actuó en Hospital Central (Telecinco, 2000-2012) y La señora (TVE, 2008-2010) o Diana Palazón en $\mathrm{Al}$ salir de clase (Telecinco, 1997-2002) y de nuevo en Hospital Central.

Cabecera. No existía una relación entre las cabeceras de ambas producciones. Mientras que en Pasión de Gavilanes se presenta a los personajes en primeros planos y 
de movimiento al son de la canción Fiera inquieta de Ángela María Forero; en Gavilanes la cabecera consistía únicamente en la superposición del título Gavilanes sobre la pantalla acompañado de una música instrumental.

Episodio piloto. El número de tramas era mayor en la versión española. Entre ellas, había una carga mayor de tramas de misterio, como reconocía la propia productora Gestmusic (2010, web): “Se mantendrá la trama central que ha convertido a Pasión de Gavilanes en un éxito internacional, aunque variarán algunos de sus planteamientos. Así, primará el clima de suspense e intriga, con nuevas tramas que sorprenderán a los seguidores de la versión original".

En el episodio piloto de la versión original se planteaba el conflicto de Libia, hermana de los tres atractivos hermanos Gavilanes, que estaba enamorada de don Bernardo Elizondo, padre de tres hijas jóvenes, y del cual se quedará embarazada. Al enterarse Libia de la muerte de su amante y sufrir la humillación de la viuda de don Bernando, decide suicidarse. Al mismo tiempo, se introducían varias tramas amorosas que se desarrollarán a lo largo de la telenovela: el matrimonio no consumado de Norma, hija mayor del terrateniente fallecido; y el enamoramiento platónico de Franco, hermano de Libia, por una camarera y cantante de un bar del pueblo.

En el primer episodio de la adaptación española, titulado "Se avecina una tragedia", el hilo argumental coincidía con la original pero se desarrollaba en mayor medida, ya que, una vez enterrada la hermana de los tres jóvenes hermanos, estos jurarían venganza a la familia Elizondo, y decidirían conseguir trabajo en su empresa para poder destruir su clan familiar desde dentro.

Desde este primer capítulo de la adaptación se anticipaban las relaciones amorosas entre los personajes, ya que los tres hermanos tienen encuentros individuales con las hermanas Elizondo.

La primera escena de ambas producciones no es exactamente igual, pero sí cumple la misma función narrativa: recoge un encuentro a escondidas entre la joven Libia (Lidia en España) y el señor Bernardo.

Estética. En la puesta en escena pudimos apreciar los casi 10 años de diferencia entre la adaptación y la versión original, siendo el decorado y los vestuarios mucho más modernos. Además, la historia se adaptaba a la cultura local, por ejemplo: en Colombia la familia Eliozondo cosechaba café y en España aceite de oliva.

En cuanto al número de decorados, las dos producciones tenían bastantes localizaciones y escenarios, notándose, al menos en el capítulo piloto, una cantidad superior en la versión española (se han contando siete escenarios fijos en lugar de los cinco de la producción original). Debido a este salto en el tiempo, 2003-2010, el atrezzo en general era distinto, siendo más urbanita en el remake y situándose la trama en una zona costera.

Diálogos. También el tratamiento del tema de la hermana de los gavilanes que fallece fue tratado de distinta forma, siendo abordado en Pasión de Gavilanes desde una 
Televisión - Series de televisión - Proceso productivo - Producción audiovisual Programa de entretenimiento - Programación televisiva

perspectiva machista, paternalista y violenta por parte de los tres hermanos; en contraposición, en la versión española, el personaje de Lidia era una joven moderna e independiente, estudiante universitaria, que no se responsabiliza de sus hermanos en las tareas domésticas. Asimismo, las tres hermanas Elizondo en la versión española eran mujeres ambiciosas y de provecho, que desarrollaban individualmente su carrera profesional y académica. Sin embargo, en la versión colombiana, las tres hermanas que caen enamoradas de los gavilanes eran meras beneficiarias de la herencia que les dejó su padre.

6.1.5. El don de Alba (Telecinco, 2013)

\begin{tabular}{|l|l|}
\hline Título: El don de Alba & Título Original: Ghost Whisperer \\
\hline Cadena: Telecinco & Cadena: CBS (EE.UU.) \\
\hline Periodo: 2013 & Periodo: 2005-2011 \\
\hline Género: drama & \\
\hline
\end{tabular}

Características formales. La versión española fue la primera producción serial que Walt Disney Pictures hacía en España, en colaboración con Telecinco. Ghost Whisperer se estrenó en la CBS estadounidense en 2005 y alcanzó cinco temporadas, cada una con una media de 22 episodios. En España, la temporada tuvo una menor duración, con 13 entregas, si bien cada una de ellas pasaba de los 45 minutos de la original a más de 70 .

Personajes En la versión norteamericana la protagonista era Jennifer Love Hewitt, una actriz estadounidense de gran popularidad. En la versión española, los actores eran jóvenes promesas del panorama televisivo nacional. En el papel de Alba figuraba Patricia Montero, que ya había participado en diversas series, como en Yo soy Bea en el papel de "Be". Por su parte, Martín Rivas, que daba vida al joven médico Pablo, era reconocido por el público juvenil por haber dado vida a Marcos, uno de los personajes más recordados de la ficción El Internado (Antena3, 2007-2010).

Cabecera. La cabecera de las dos producciones era bastante similar, siendo Melinda y Alba (cada una en su respectiva serie) las únicas protagonistas del mundo de fantasía que se muestra en esta presentación.

Episodio piloto. El toque de <fantasía cercano a un producto infantil envuelve la vida de Alba, siendo quizás este el factor principal de diferenciación entre las dos producciones, puesto que aunque Ghost Whisperer era una serie que trata sobre espíritus y hechos sobrenaturales, el tratamiento de los mismos hace que sea un producto dirigido a todos los públicos, no sólo infantil.

El episodio piloto español planteaba varias incógnitas a la audiencia, para desarrollar las tramas a lo largo de los siguientes capítulos. Exponía, de una manera más rápida que en la versión original, diversos misterios y dilemas importantes para el transcurso de la serie. En este capítulo Alba descubría su don sobrenatural y tenía 
que hacer frente a la muerte de su abuela, la única persona con la que compartía tal secreto.

En Buenavista, localidad donde transcurría El don de Alba existía una niña llamada Alicia, que había perdido traumáticamente a su madre, y que también veía a los espíritus "en tránsito". Por ello, creaba un vínculo con Alba. En la versión original, la protagonista, Melinda, creaba también un vínculo con un personaje infantil a partir de la cuarta temporada, que sería su hijo. Quizás esta decisión de que el personaje infantil fuese una niña de la localidad y no la hija de la protagonista, responde a que la producción de Walt Disney, quería representar a Alba como un personaje muy joven sin ningún conflicto dramático relacionado con la maternidad, cercano al público infantil y juvenil al que estaba más dirigido el formato español.

Teniendo en cuenta esta hipótesis (adaptación se enfoca a un público potencial de menor edad que Ghost Whispere), se explica que Alba iniciara una relación de atracción con Pablo, un joven médico de la localidad, en vez de estar casada con él, como ocurría en Entre fantasmas entre Melinda y Jim Clancy. Asimismo, al comienzo del capítulo se revela el día que Alba descubre que tiene un don, al poder hablar con el espíritu de un amigo que murió siendo niño. En la serie protagonizada por Jennifer Love Hewitt, el difunto es un hombre de avanzada edad.

La primera escena del piloto adaptado no corresponde con la primera escena del capítulo de Ghost Whisperer en el que estaba inspirado, el tercero de la primera temporada, pero sí se correspondía con la primera escena del primer capítulo, que reflejaba el momento en el que ambas protagonistas descubren su don. De igual manera, en este primer episodio español ya se anunciaba la existencia de un espíritu oscuro que intentaba llevar a las almas hacia el lado tenebroso, trama que en la versión original no sería descubierta hasta pasar el ecuador de la primera temporada.

Estética. Se utilizaron muchos encuadres, planos y recursos narrativos de la producción norteamericana, como los continuos flashbacks. Los decorados eran muy parecidos, dado que ambas protagonistas trabajaban en una tienda de antigüedades, y gran parte del capítulo trascurre en un hospital mental. El atrezzo era muy similar y, junto con el vestuario, presentaban a los personajes de Melinda y Alba como mujeres jóvenes y atractivas.

Tanto en la versión adaptada como en la original, las historias transcurrían en dos localidades ficticias, Grandview, en EE.UU. y Buenavista5 ${ }^{5}$ en España.

Diálogos. La trama principal del episodio original "Espíritu Dividido" recogía la misión que Melinda y Alba, respectivamente, debían llevar a cabo para que el espíritu adolescente de una gemela que murió ahogada pueda abandonar el purgatorio y dejar que su hermana viva pueda recuperarse. Este relato estaba plasmado en la adaptación de una manera muy similar, usándose la mayoría de los diálogos de manera literal.

\footnotetext{
${ }^{5}$ Nótese la traducción parcial del nombre como muestra de la adaptación del formato.
} 
Televisión - Series de televisión - Proceso productivo - Producción audiovisual Programa de entretenimiento - Programación televisiva

\subsection{Series cuyo original no se haya emitido en España}

\subsubsection{Hermanos y detectives (Telecinco, 2007-2008)}

\begin{tabular}{|l|l|}
\hline Título: Hermanos y detectives & Título Original: Hermanos y detectives \\
\hline Cadena: Telecinco & Cadena: Telefé (Argentina) \\
\hline Periodo: 2007-2009 & Periodo: 2006 \\
\hline Género: dramedia & \\
\hline
\end{tabular}

Características formales. Ambas producciones pueden ser encuadradas en el género de suspense-acción. La idea original se planificó para una serie de 10 capítulos, como efectivamente sucedió en la producción argentina. En España, al registrar el formato buenos datos de audiencia, se decidió hacer una segunda temporada con guiones originales, momento en el cual comenzó a descender la cuota de espectadores.

Personajes. En las dos producciones participaron actores populares a nivel nacional y cuya trayectoria les hizo ser rostros conocidos para las audiencias. En el caso de la versión argentina, Rodrigo de la Serna, quien interpreta a Franco Montero, era conocido por su trabajo en largometrajes de éxito, como Diarios de una motocicleta (2004). En España, el actor que encarnaba al hermano mayor es Diego Martín, era conocido por sus papeles en series como Aquí no hay quién viva (Antena 3, 2003-2006) o Policías, en el corazón de la calle (Antena 3, 2000-2003).

Pero el dato que vinculaba directamente la versión original con la adaptación española era que Rodrigo Noya, el joven actor que da vida a Lorenzo, el hermano prodigio del detective, intervenía en las dos versiones, habiendo participado en la producción argentina en 2006 y en la española desde 2007. Este último dato era vinculante entre las producciones y se hacía más notorio cuando en la adaptación española, Montero descubre que su padre vivió sus últimos años en Argentina, donde tuvo un hijo, Lorenzo, que pasaría entonces a su custodia.

En la versión española existía un personaje femenino entre los agentes de policía, inexistente en la versión argentina. Este personaje no tenía la finalidad de crear una trama amorosa, respondiendo su existencia a dotar de modernidad e igualdad profesional para ambos sexos al Cuerpo Nacional de Policía de España.

Cabecera. La cabecera era exactamente igual en ambos productos, cambiando únicamente al actor Rodrigo de la Serna por Diego Martín.

Episodio piloto. El episodio inicial de las dos producciones se titulaba "El profesor Fontán" y narraba el asesinato de un joven escritor por parte de su profesor de literatura, movido por la ambición de robarle su primera obra. La investigación del asesinato era asignada a Montero, un joven policía, y a su compañero Mansilla, pero quien descubrirá realmente al autor de los escalofriantes hechos será Lorenzo, el hermanastro de Montero, que llegaba de improvisto y que deslumbra a todos con su ingenio. 
Las escenas de comienzo eran literalmente iguales, con el profesor de literatura ensayando en su casa entre tinieblas los pormenores del asesinato que va a cometer. De igual manera, el número de tramas de las dos producciones era el mismo: tres. La principal, que era la relación entre Montero y su nuevo hermano Lorenzo; la temática, que cambiará en cada capítulo y que era la investigación de un caso concreto; y una amorosa que surgirá con la camarera del bar que Montero frecuenta. Es destacable cómo, a pesar de que en las adaptaciones españolas siempre se presenta una trama amorosa en los primeros compases narrativos, en el caso de Hermanos y detectives, el guión no fue modificado por esta vía, haciéndose únicamente un pequeño comentario sobre la belleza de la camarera en el piloto, y desarrollando la trama en los siguientes capítulos.

Estética. La similitud del atrezzo en las dos producciones era muy significativa, además de respetar la construcción de los planos y el esquema de montaje de la historia. También compartían el número de decorados: tres fijos (el bar, la casa de Montero y la comisaría), tres localizaciones específicas (la casa de profesor, la escena del crimen y la estación de tren), y cuatro exteriores.

Diálogos. No había apenas diferencias entre los diálogos de la serie original y su adaptación, empleándose, en muchos casos, los mismos extractos del guión. Se modificaron únicamente algunos términos propios de la variedad del idioma correspondiente a Argentina o a España.

\subsubsection{Sin tetas no hay paraíso (Telecinco, 2008-2009)}

\begin{tabular}{|l|l|}
\hline Título: Sin tetas no hay paraíso & Título original: Sin tetas no hay paraíso \\
\hline Cadena: Telecinco & Cadena: Caracol TV (Colombia) \\
\hline Periodo: 2008-2009 & Periodo: 2006 \\
\hline Género: drama & \\
\hline
\end{tabular}

Personajes Esta serie supuso, como en otros casos analizados anteriormente, el auge de jóvenes actores españoles, debido al gran éxito de la producción a lo largo de los dos años que estuvo en antena. Es el caso de Amaia Salamanca (Catalina), posteriormente protagonista de la serie Gran Hotel; y Miguel Ángel Silvestre, que a raíz de su papel en la serie dio el salto al cine. En la producción original, los protagonistas, María Adelaida Puerta en el papel de Catalina, no era conocida para el público colombiano, sin embargo, Marlon Moreno, que interpretaba a "El Titi" (símil de "El Duque" en España) era conocido por su participación en diversas telenovelas.

Cabecera. Desde la cabecera de la serie se comienzan a percibir diferencias entre la versión original colombiana y su adaptación, siendo la presentación original mucho más oscura y conteniendo un mensaje trágico; el tema musical Agujero, cantando por Jox, abordaba la pobreza en la que muchas jóvenes colombianas se encuentran y de la que quieren escapar a cualquier precio, aunque sean convertidas en barbies como las mostradas en las imágenes, al servicio de los narcotraficantes de su país. En la 
Televisión - Series de televisión - Proceso productivo - Producción audiovisual Programa de entretenimiento - Programación televisiva

producción española, el comienzo era mucho menos provocador, afirmándose desde la cabecera que el remake está basado en una historia de amor, mostrándose una gama de tonos rosáceos y transmitiendo un mensaje de esperanza y romanticismo con la canción Hoy me faltas tú de Edurne.

Episodio piloto. El número de tramas que se presentaba en el primer capítulo de la versión española era mayor que en la versión original. En el primer capítulo del remake se contaba la llegada de "El Duque" a la ciudad; la introducción del hermano de Catalina en carreras de coches; el encuentro entre Catalina y Rafael "El Duque"; el asesinato de una mujer en casa del joven narcotraficante y la posterior investigación minuciosa por parte de un policía; la llegada de Jairo, el narcotraficante más temible de Colombia a la ciudad; la actitud de proxeneta de Yessica; la relación de "El Duque" con su torpe hermano y los deseos profesionales que la madre de Catalina quiere llevar a cabo.

El capítulo piloto de la versión original era mucho más crudo. Cuenta el deseo imperioso de la joven Catalina de someterse a una operación de aumento de pecho, con el objetivo de llegar a ser una meretriz de alguno de los hombres adinerados de Colombia, como hacen sus amigas. Se abordaban las malas compañías que Catalina comienza a frecuentar (como Yessica); los problemas con su novio al no querer perder la virginidad con él, puesto que está decidida a hacerlo por dinero; o el rechazo de "El Titi" (personaje equivalente a "El Duque" español) hacia Catalina por tener ésta los pechos pequeños.

A tenor de estos datos se apreciaba cómo, una vez más, en la versión española se hace un mayor hincapié en plantear una relación de amor platónico que enganche al público.

Estética. La época de ambientación era la misma ya que las dos producciones se sitúan en la misma época, pero en el proceso de adaptación, se ha creado una diferencia social. Así, la versión original mostraba un barrio marginal de Colombia y en el remake la historia se desarrollaba en espacios donde prima la clase media.

En cuanto al uso de decorados y localizaciones, la versión española contó con más recursos que su original, grabando en más de seis interiores y cuatro espacios públicos, en contraposición de los tres interiores y dos espacios exteriores del serial colombiano.

Diálogos. En cuanto a localismos, es obvio, como ocurre en Pasión de Gavilanes, que la versión original tenía un contenido machista superior a la adaptación, que a pesar de que también existe, está mejor disfrazado. Así, el tema de la prostitución en Colombia es tratado abiertamente, mientras que en España se intenta dejar de lado. 
6.2.3. Camera Café (Telecinco, 2005-2009)

\begin{tabular}{|l|l|}
\hline Título: Camera Café & Título Original: Camera Cafe \\
\hline Cadena: Telecinco & Cadena: M6 (Francia) \\
\hline Periodo: 2005-2009 & Periodo: 2001-2004 \\
\hline Género: comedia & \\
\hline
\end{tabular}

Características formales. Camera Café se emitió primero con una periodicidad semanal, pero fue con su paso a la programación diaria en el access prime time cuando cosechó sus mayores cuotas de éxito, convirtiéndose en una de las opciones con mayor preferencia por parte de los espectadores a lo largo de más de cuatro años. La estructura narrativa de cada capítulo era exactamente la misma, y constaba de varios sketches (nunca más de media docena) de una duración entre cuatro y cinco minutos.

Personajes. En cuanto a los comediantes, Camera Café fue una cantera de actores. Además de recuperar al actor Luis Varela (Gregorio Antúnez, director gerente en la serie), otros intérpretes utilizaron la serie como una lanzadera para sus carreras en la televisión, como fue el caso de Arturo Valls, Carolina Cerezuela o Ana Milán.

Cabecera. La serie tenía una presentación muy sencilla. En ambos casos, la cabecera mostraba el proceso de elaboración de un café en la máquina de la oficina. Entre los diferentes sketches, se introducían cortinillas en las que se mostraban procesos simplificados del café, normalmente interrumpidos o aderezados por algún elemento 'extraño'.

Episodio piloto. En cada sketch de la entrega se desarrollaba una trama, siendo la primera de todas en la versión española la charla que mantienen el encargado de ventas Jesús Quesada (Arturo Valls) y el jefe de compras y representante sindical Julián Palacios (Carlos Chamarro), sobre las desavenencias del primero con su hijo. En la versión francesa, el primer capítulo se llamaba Le nouve machine y servía como un acercamiento de los personajes al espectador a través de la nueva máquina de café de la empresa, ante la que van desfilando. Una vez más, por lo tanto, el capítulo piloto de la adaptación no concordaba con el de la original.

Estética. Tanto la decoración como los personajes eran muy similares en las dos versiones, siendo prácticamente idéntica la sala de reunión ante la máquina de café que constituye el único escenario. Aspectos como la cabecera, las cortinillas entre sketch y sketch, el diseño de los créditos y del título contaban con una gran similitud. Además, la mayor característica de este formato, la cámara fija, se respetaba de igual manera en ambas versiones.

Diálogos. Cámera Café fue una adaptación que contó con aspectos muy similares a la versión francesa en cuanto a la idea, los personajes y el proceso narrativo, pero no en lo que se refería al guión. Éste tenía un gran trabajo de modificación con la finalidad de adaptar la realidad empresarial española con sus tópicos y referencias coyunturales. 
Televisión - Series de televisión - Proceso productivo - Producción audiovisual Programa de entretenimiento - Programación televisiva

6.2.4. La chica de ayer (Antena 3, 2009)

\begin{tabular}{|l|l|}
\hline Título: La chica de ayer & Título Original: Life on Mars \\
\hline Cadena: Antena3 & Cadena: BBC (UK) \\
\hline Periodo: 2009 & Periodo: 2006-2007 \\
\hline Género: dramedia & \\
\hline
\end{tabular}

Características formales. Life on Mars narraba la historia de Sam, un joven policía que tuvo un accidente de coche en 2006 y cuando despierta se encuentra con que ha retrocedido en el tiempo hasta el 1973. La razón del suceso se iba explicando a lo largo de la serie, pero desde el primer capítulo se va entendiendo como la causa tiene que ver con un asesino que quiere hacer daño a su novia en la época actual (2006), por lo que él debe cambiar algo del pasado para que no suceda nada de esto en el presente. En La chica de ayer, Samuel viaja hasta el 1977, en plena Transición española. De manera contraria a la versión original, la trama principal era la historia de amor entre el protagonista y Ana Valverde, una compañera de la comisaría. Además, al final del capítulo, Samuel mataba al personaje que en la versión original intenta hacer daño a su novia de la actualidad, por lo que a partir de ese punto el remake se alejaba de manera considerable a la idea original.

Personajes. La serie española contaba con Ernesto Alterio en el papel de protagonista y Manuela Velasco en el de su compañera de trabajo, actores conocidos para los espectadores españoles. Sam es interpretado por John Sim, asiduo de las series de televisión británicas.

Episodio piloto. La serie británica comenzaba con una imagen de Sam, el protagonista, sentado sobre la mesa de su despacho, diciendo "Me llamo Sam Tyler. Tuve un accidente y me desperté en 1973. ¿Estoy loco, en coma, o viajé en el tiempo? Pasara lo que pasara, es como si hubiera aterrizado en otro planeta. Quizás si descubriera la razón, podría volver a casa". En la versión española, el comienzo era igual, pero el contenido del monólogo que inicia la serie es distinto, adaptándolo a un contexto más localista:

1977 fue un gran año. Bueno, es cierto que no existían los móviles ni los MP3, por supuesto no había Internet y, en fin, el divorcio, el juego y muchas cosas más estaban aún prohibidos. Pero ese año se celebraron las primeras elecciones democráticas, y en las calles se respiraba un aire de optimismo. El Betis ganó la primera Copa del Rey que antes se llamaba del Generalísimo. Ese año se estrenó La Guerra de las Galaxias y en todas las emisoras se escuchaba Gavilán o paloma. En 1977 yo tenía cinco años, ahora he vuelto con 37 y todavía no sé cómo ha pasado.

El número de tramas en las dos versiones era el mismo, tres: Sam/Samuel tienen un accidente y retroceden 33 años en el tiempo y debe averiguar cómo volver; Sam/Samuel deben buscar al asesino que quiere herir a su novia en el futuro; Sam/Samuel asientan las bases de una trama amorosa con una trabajadora de la comisaria. Era en este punto, en la trama amorosa, donde las adaptaciones españolas hacían más hincapié y donde solían surgir los problemas en las traslaciones de guión. 
En cuanto a la "españolización" de la serie lo que se pretendió fue potenciar más ciertas tramas que en la original eran más sutiles como el humor y la relación amorosa entre Samuel y Ana. El personaje de Samuel era el encargado de reforzar esos guiños humorísticos cayendo en ciertas ocasiones en una sobreactuación actoral. Todo el halo de misterio relacionado con la trama principal de la serie por decisión de producción se redujo al mínimo. Las escenas más propias del género de cienciaficción se mitigaron en la adaptación perdiendo, en este punto, parte de la esencia única de Life on Mars (biblia 6 de La chica de ayer en Diego y Grandío, 2011: 855).

Estética. Los decorados eran similares en las dos producciones ya que hacían una retrospectiva y conseguían una imagen muy trabajada de lo que era la Inglaterra de los años 70 y la España durante la Transición. El número de los decorados es el mismo, contando con tres fijos (comisaría, bar y casa) más otro polivalente.

Diálogos. La adaptación española partía de la misma idea, siendo un remake muy bien conseguido en cuanto a la adecuación de la mayor parte del guión a la cultura española. Aún así, no se puede obviar las ligeras modificaciones de la serie española que dotaron al producto de una personalidad que la alejaba mucho de la británica. En La chica de ayer se retrocede hasta el año 1977 y no 1973, dándole un matiz político que se percibe en el propio contexto de la adaptación, tal y como hemos visto anteriormente.

A pesar de ser un producto ambicioso de la producción televisiva española, no consiguió la suficiente repercusión en forma de audiencia (15,9\% de share) para su dilación en la parrilla televisiva a lo largo de su periodo de emisión. Aún así, se decidió emitir toda la primera temporada, compuesta por ocho capítulos.

\subsubsection{Doctor Mateo (Antena 3, 2009-2011)}

\begin{tabular}{|l|l|}
\hline Título: Doctor Mateo & Título Original: Doc Martin \\
\hline Cadena: Antena3 & Cadena: ITV (UK) \\
\hline Periodo: 2009-2011 & Periodo: 2004-2011 \\
\hline Género: dramedia & \\
\hline
\end{tabular}

Características formales. La versión original estuvo durante dos temporadas en la televisión, mientras que la española, una vez más, rentabilizó el producto por otras tres más. Existía un mayor número de personajes secundarios en la versión española, abriendo así el número de tramas e hilos narrativos que se irían desarrollando a lo largo de la serie.

\footnotetext{
${ }^{6}$ Siguiendo a Bustamante (1999, p. 212) la biblia es el “documento inicial de muchas series y seriales estadounidenses, en donde se contienen los objetivos y los núcleos narrativos y caracteres básicos, y que permite ir desgajando los episodios guardando siempre una coherencia básica”.
} 
Televisión - Series de televisión - Proceso productivo - Producción audiovisual Programa de entretenimiento - Programación televisiva

A pesar de que el remake español duraba casi 30 minutos más que el primer capítulo original, se apreció un buen trabajo de traducción de guión y adecuación a la versión española, puesto que sin diferir en exceso (muchas conversaciones, situaciones y planos son idénticos) fueron capaces de dar un toque local muy sutil, razón a considerar en la buena acogida de esta adaptación por parte del público español.

Personajes. En cuanto a actores, en la adaptación se apostó por actores consagrados en el mundo de la comedia, como Gonzalo de Castro (7 vidas, Telecinco, 1999-2006) en el papel de doctor, Rosario Pardo en el papel de Tía Juana y Natalia Verbeke, como Adriana, la profesora del pueblo. En la versión inglesa contaron con Martin Clunes en el papel principal, actor de dilatada carrera cinematográfica con papeles en películas como Shakespeare in love (John Madden, 1999).

Cabecera. Respecto a la cabecera, cada una era original a pesar de tener, en la versión española, reminiscencias de la inglesa. La producción original optó por una música instrumental mientras se iban exponiendo escenas de paisajes del ficticio Portween. En la versión nacional, las imágenes iban acompañadas del tema Elixir, del grupo Zeno and Destoics y además de aparecer los pastos asturianos, había escenas donde salía el doctor en San Martín del Sella, pueblo también ficticio donde ocurre la historia de la versión española.

Episodio piloto. El primer capítulo en las dos producciones cuenta con tres tramas que asientan lo que será la vida de Martin/Mateo en su nuevo destino profesional: una era justamente eso, su llegada al pueblo y su relación con los vecinos; su primer trabajo como doctor, que tendría que tratar una ginecomastia masculina y que sería el hilo central del capítulo, y por último su relación con la profesora de la localidad.

Existía una vinculación en la versión española con su original, ya que cuando Mateo entraba al pueblo, San Martín del Sella, se veía como en un cartel pone que era una población hermanada con Portween, localidad donde se narra la versión original.

En ambas versiones, los capítulos pilotos partían de la misma escena. Mateo y Martin aparecen en una sala de cirugía de grandes dimensiones, siendo analizados por un grupo de jóvenes estudiantes de medicina y con un gran séquito de enfermeras y apoyos médicos alrededor, cuando de repente descubre que sufren hemofobia. Éste sería un punto de inflexión en su vida, lo que le hará decidir tomar un nuevo rumbo en un pequeño pueblo costero.

Estética. En cuanto al número de localizaciones, España tenía un mayor número, contando con seis fijos (frutería, colegio, vivienda del doctor, finca de tía Juana, sala de radio y bar) y diversos exteriores mientras que en la versión inglesa no existía la frutería, ni la sala de radio ni el bar.

Diálogos. El tipo de diálogo utilizado en las dos versiones era parecido, todos giran alrededor de Mateo/Martin y tienen como finalidad explicar al espectador las razones que han llevado al doctor hasta ese pueblo y la manera de vivir de la población de la pequeña localidad. Los guiones, si bien siendo muy parecidos, difieren en algunas ocasiones. En la versión española, el capítulo duraba 20 minutos 
más, por lo que inevitablemente existía una ampliación de guión en el remake creada de manera original por los guionistas de la versión española.

\subsubsection{Lalola (Antena 3, 2008-2009)}

\begin{tabular}{|l|l|}
\hline Título: Lalola & Título Original: Lalola \\
\hline Cadena: Antena3 & Cadena: América TV (Argentina) \\
\hline Periodo: 2008-2009 & Periodo: 2007-2008 \\
\hline Género: comedia & \\
\hline
\end{tabular}

Características formales. El remake español era muy similar a la versión original, aprovechándose de la mayor parte del guión. Cabe destacar que las adaptaciones desde series sudamericanas sufren una menor modificación del guión que aquellas procedentes de países de lengua extranjera.

Personajes. La adaptación contaba con actores que en la época de su producción eran poco conocidos en el panorama televisivo español, formando el dúo protagonista Octavi Pujades y Marina Gatell. Sin embargo, en el caso de la versión original argentina, la actriz que encarna a Lola, Carla Peterson, era una actriz que contaba con una trayectoria importante en la televisión argentina.

Cabecera. Ambas contaban con la misma música de cabecera y cierre, a cargo de la banda argentina Miranda!

Episodio piloto. Las dos series trataban los mismos asuntos en el capítulo piloto: la transformación de Lalo en Lola mediante una maldición procedente de un amor fugaz por ser un seductor frío y desprovisto de sentimientos con las chicas. También se narraba la ayuda prestada por parte de su amiga, que había estado enamorada de él toda la vida y el proceso de adaptación en la empresa con su nuevo cuerpo de mujer. Es justamente en la empresa donde se asienta las bases de lo que desarrollará la trama amorosa de la serie: uno de los trabajadores de la empresa, el joven más criticado por Lalo y sus amigos por no tener conquistas conocidas, se fija en Lola, la prima de Lalo que ha llegado para suplir su ausencia.

Existía una vinculación de la adaptación a su original, puesto que la excusa que Lola pone al jefe de la empresa sobre dónde está Lalo, se basa en un viaje urgente a Argentina, donde vive su padre, el cual se encuentra enfermo.

Estética. Tanto la decoración como las localizaciones eran muy similares y las dos versiones contaban con tres escenarios fijos: la empresa, la casa de Lola y la sala de radio donde trabaja su amiga.

Diálogos. Al igual que ocurre en otras adaptaciones procedentes desde Sudamérica, como Hermanos y detectives (Telecinco, 2007-2009), los diálogos eran los mismos en las dos versiones, difiriendo mínimamente en las ocasiones que lo precisen, como cuando Lola habla con el jefe y dice que Lalo está en Argentina por problemas 
Televisión - Series de televisión - Proceso productivo - Producción audiovisual Programa de entretenimiento - Programación televisiva

familiares y sin embargo, en la versión original, Lola decía que Lalo está de recorrido por Europa.

\section{CONCLUSIONES}

Después de este análisis en el que hemos podido identificar tanto el remake como la versión original de las series de ficción analizadas, así como conocer que elementos son adaptados y cuáles no, dependiendo de cada caso de estudio, es el momento de responder a los objetivos de investigación planteados en el apartado anterior.

Respecto al patrón o lógica de los remakes, podemos afirmar que la elección de un formato extranjero para su adaptación en España responde, entre otras muchas razones, al éxito comprobado de la idea original en el país desde el que procede. Esto está estrechamente relacionado con el cambio de sistema televisivo que se estableció en 1990 con la instauración de cadenas de televisión privadas, Antena 3 y Telecinco. A partir de la instauración del oligopolio televisivo, surge la competencia por registrar mayores datos de audiencia y en esa lucha es donde se cambia el sistema de producción de ficción televisiva y se apuesta, cada vez más, por la adaptación de producciones internacionales de éxito probado en su país original.

Además, se deja de lado la producción de series de ficción de corta duración por otro que consiga un mayor porcentaje de 'fidelización' de la audiencia, creando así formatos de larga duración. Así es el caso de Yo soy Bea (Telecinco, 2006-2009) telenovela emitida en la sobremesa española de la que se crearon 600 capítulos más de los 169 que componía la versión original Yo soy Betty, la fea (RCN, 1999-2001). Cuando una serie de ficción registra datos positivos de audiencia lo común es que se alargue en el tiempo, escribiéndose los guiones paralelamente a su emisión.

De esta forma, hemos visto como priman los elementos que ayudan a crear lazos de fidelización con la audiencia sobre el mantener la similitud entre el remake y la idea original.

1). El rasgo más característico que se repite en todas los remakes analizados es el asentamiento en la versión española de las bases de una historia romántica, haciendo que esto provoque en ocasiones una diferencia narrativa entre la historia contada en la versión original y la adaptación, como ocurre, por ejemplo, en Sin tetas no hay paraíso (Telecinco, 2008- 2009). Hacer uso del amor en todas las series de ficción españolas y que éste sea tratado desde una perspectiva idealizada y romántica responde a otra estrategia de adhesión de la audiencia española al formato emitido. El amor es un género desarrollado en todas las esferas artísticas por ser un punto de anclaje para los espectadores, puesto que todos los humanos contamos con ese sentimiento.

2). Otro rasgo de 'españolización' es la supeditación de elementos políticos. El uso recurrente de comentarios o contextualizaciones políticas de algunas adaptaciones, se contradicen con el intento de alejar el formato, en otros casos, de cualquier 
connotación en este aspecto. Así el ejemplo más claro de vinculación política se encuentra en La chica de ayer (Antena 3, 2010) adaptación de Life of Mars (BBC, 2006). Esta diferencia del tratamiento político responde a las contextualizaciones históricas de las series. Es decir, España es un país que produce varias ficciones ambientadas en épocas pasadas y en esos casos sí que procede hablar de la política de ese momento, como ocurre en La chica de ayer.

3). También existe un alargamiento de los capítulos de la versión adaptada casi sistematizado, que es más destacado en aquellos formatos que son emitidos en prime time. La extensión, que puede superar en más de 30 minutos respecto a su original, se crea, entre otras razones, para que ese formato acapare al completo la franja horaria de máxima audiencia. Consiguiendo de este modo que aquellos espectadores fieles a un formato no se 'fuguen' a otra cadena a lo largo del prime time. Es un aspecto que se da incluso en las sitcoms (que suelen contar con una duración menor a los 30 minutos) como ocurre, por ejemplo, en Las chicas de oro (TVE, 2010).

4). Como último rasgo se hablará del uso reiterado de los mismos actores para dar vida a personajes similares en productos audiovisuales diferentes. Suele darse en ocasiones en las que un actor ha formado parte del elenco de una serie con éxito. Se puede nombrar como uno de los casos más ejemplares, el de Alexandra Jiménez: fue primeramente África en Los Serrano (Telecinco, 2003-2008), también fue la protagonista de La pecera de Eva (Telecinco, 2010-2011), dando vida a una psicóloga excéntrica y borde. Después de este proyecto, formó parte de la adaptación Cheers (Telecinco, 2010-2011) donde repetía con una personalidad similar a las de las anteriores, y por lo tanto en las tres series, consecutivamente, representó a una chica fría y distante. La intención que se puede extraer de este sistema es la de crear a los espectadores una referencia común entre las series españolas y los remakes, "españolizando" de este modo a los personajes de una serie basada en una idea extranjera a través del uso de actores 'encasillados' y reconocidos por la audiencia española.

Vemos así como en España la labor de adaptar una serie conlleva un arduo trabajo, ya que además de hacer los diálogos o las situaciones más cercanos a temas locales, estas producciones deben adaptarse a su vez a las características propias de la ficción de nuestro país, la cual, a lo largo de los años ha ido caracterizándose por una serie de elementos que la han marcado y diferenciado de otros países. Como afirman Puebla, Carrillo e Íñigo (2012, p. 9) "Spain is different y en la ficción televisiva no podía ser de otra manera. Entre otros aspectos, España no tiene una duración estándar en sus series, ni en minutos por capítulos, ni en número de episodios por temporada."

Por tanto, aunque los remakes necesitan adaptar una serie de elementos para poder emitirse en las cadenas españolas, es la necesidad de lograr altos índices de audiencia lo que hace que se juegue con una serie de elementos que hacen que el público español siga o no siga una serie. De ahí que se creen series corales, donde se vean identificados todos los miembros de una familia; el aumento del número de tramas 
Televisión - Series de televisión - Proceso productivo - Producción audiovisual Programa de entretenimiento - Programación televisiva

para que todo el mundo tenga una historia a la que engancharse o se realice un estiramiento de capítulos por temporada siendo su número indeterminado y variable.

\section{REFERENCIAS}

Bustamante, E. (1999). La televisión económica: financiación, estrategias y mercados. Barcelona: Gedisa.

Diego, P. (2010). La ficción en la pequeña pantalla. Cincuenta años de series en España. Pamplona: Eunsa.

Formula.tv (2010). Conoce a los protagonistas españoles de 'Pasión de Gavilanes'. Consultado el 10 de noviembre, 2013. Disponible en: http://www.formulatv.com/noticias/14129/conoce-a-los-protagonistas-espanoles-depasion-de-gavilanes/

Guerrero, E. (2009). El desarrollo de proyectos audiovisuales: adquisición y creación de formatos de entretenimiento. Comunicación y sociedad, 23 (1), 237-273.

Puebla, B. Carrillo, E. e Íñigo, A. (2012). Ficcionando. Series de televisión a la española. Madrid: Fragua.

Puebla, B. Copado, P. y Carrillo, E. (2012). Una aproximación a la adaptación de las series extranjeras en España. Actas del V Congreso Internacional Latina de Comunicación Social. Tenerife: Sociedad Latina de Comunicación Social. Disponible en: http:// www.revistalatinacs.org/13SLCS/2013_actas.html

Sánchez Noriega, J. L. (2000). De la literatura al cine. Teoría y práctica de la adaptación. Barcelona. Editorial Paidós. 